\title{
Ion implantation and low-temperature epitaxial regrowth of GaAs
}

\author{
M. G. Grimaldi, a) B. M. Paine, and M-A. Nicolet \\ California Institute of Technology, Pasadena, California 91125 \\ D. K. Sadana \\ Lawrence Berkeley Laboratory, University of California, Berkeley, California 94720
}

(Received 17 November 1980; accepted for publication 27 February 1981)

\begin{abstract}
Channeling and transmission electron microscopy have been used to investigate the parameters that govern the extent of damage in ion-implanted $\mathrm{GaAs}$ and the crystal quality following capless furnace annealing at low temperature $\left(\sim 400^{\circ} \mathrm{C}\right)$. The implantation-induced disorder showed a strong dependence on the implanted ion mass and on the substrate temperature during implantation. When the implantation produced a fully amorphous surface layer the main parameter governing the regrowth was the amorphous thickness. Formation of microtwins after annealing was observed when the initial amorphous layer was thicker than $400 \AA$. Also, the number of extended residual defects after annealing increased linearly with the initial amorphous thickness and extrapolation of that curve predicts good regrowth of very thin $(<400 \AA) \mathrm{GaAs}$ amorphous layers produced by ion implantation. A model is presented to explain the observed features of the low-temperature annealing of GaAs.
\end{abstract}

PACS numbers: $68.55 .+\mathrm{b}, 61.70 . \mathrm{Tm}, 61.80 \mathrm{Mk}, 61.16 . \mathrm{Di}$

\section{INTRODUCTION}

Ion implantation followed by solid-phase epitaxial regrowth is of considerable interest as a technique for introducing $n$-type impurities into GaAs. It has generally been found that best electrical activity is achieved when the substrate is held at temperatures of a few hundred ${ }^{\circ} \mathrm{C}$ during the implantation. ${ }^{1-3}$ Also, best crystal quality and electrical activity after furnace annealing have been obtained with annealing temperatures above $600^{\circ} \mathrm{C} .^{2,4-6}$ However, it has recently been shown by Williams et al. ${ }^{7.8}$ that under certain circumstances good crystal quality can be achieved with implantations at room temperature and below followed by annealing at relatively low temperatures $\left(180-400^{\circ} \mathrm{C}\right)$. In an attempt to understand this good regrowth, we have conducted a detailed investigation of the parameters that may govern the extent of damage in ion-implanted GaAs and the crystal quality following low-temperature furnace annealing.

\section{EXPERIMENTAL}

Semi-insulating $\langle 100\rangle$ wafers of $\mathrm{Cr}$-doped $\mathrm{GaAs}$ from the same boule were cleaned organically and implanted with $\mathrm{Si}^{+}, \mathrm{S}^{+}$, and $\mathrm{Ar}^{+}$ions at energies of 80,80 , and $100 \mathrm{keV}$, respectively, to doses of $10^{14}-10^{16}$ ions $\mathrm{cm}^{-2}$. Substrate temperatures during implantation were $-196,27$, and $100^{\circ} \mathrm{C}$. In addition, $\mathrm{As}_{n}^{+}$molecules with energies of $60(n=1,2,4)$ and $180(n=1) \mathrm{keV}$ at $^{-1}$ were implanted to similar doses and with similar substrate temperatures. Samples were annealed without encapsulation at $400^{\circ} \mathrm{C}$ in flowing dry argon. They were analyzed at room temperature by backscattering spectrometry of $1.5-\mathrm{MeV} \mathrm{He}^{+}$ions channeled in the $\langle 100\rangle$ direction and detected at scattering angles of $125^{\circ}$ and $105^{\circ}$, the latter for improved depth resolution. Quantitative estimates of crystalline disorder before and after annealing were derived from the areas of the disorder peaks after applying a

\footnotetext{
is Permanent address: Istituto Struttura della Materia, Corso Italia 57, 95129 Catania, Italy.
}

correction for dechanneling. This procedure has been applied frequently in the channeling analysis of similar spectra for $\mathrm{Si}^{9}{ }^{9}$ Peak areas in samples that had undergone identical processing differed by no more than $4 \%$.

More detailed information about the as-implanted damage and the damage present after $400^{\circ} \mathrm{C}$ annealing was obtained by means of plan-view transmission electron microscopy (TEM). For some cases, cross-sectional TEM was also conducted in order to study the regrowth behavior of the damage/single-crystal interface. For the plan-view specimens, the chemical thinning was performed from the unimplanted side only. All of the annealed specimens were tilted to two-beam conditions for a 220 type reflection and bright field micrographs were recorded. In addition, transmission electron diffraction (TED) patterns were obtained from the plan-view specimens, but without tilting to specific orientations.

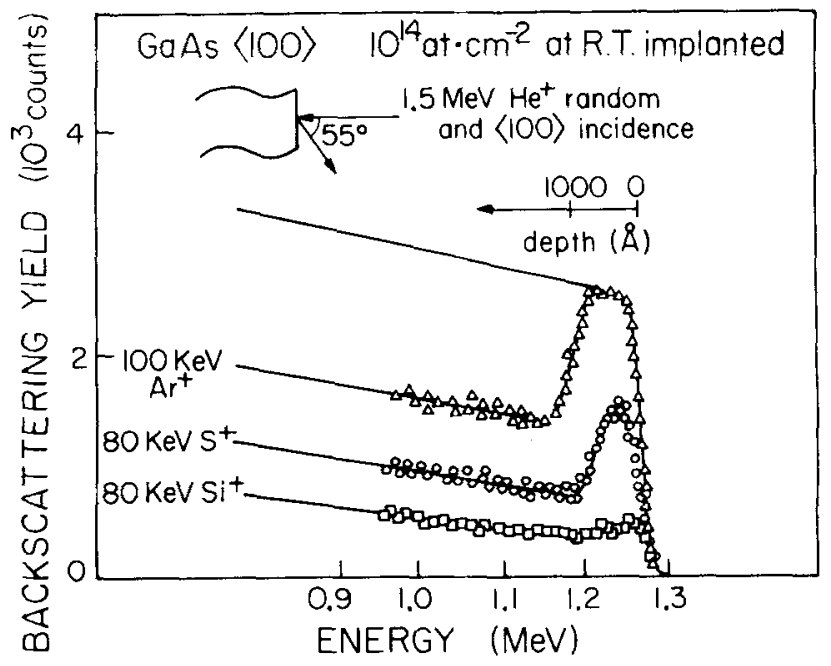

FIG. 1. Backscattering energy spectra of $1.5-\mathrm{MeV} \mathrm{He}^{+}$recorded with $\langle 100\rangle$ incidence for GaAs implanted at room temperature with $10^{14}$ ions $\mathrm{cm}^{-2}$ of $\mathrm{Ar}^{+}, \mathrm{S}^{+}$, and $\mathrm{Si}^{+}$. An increase in the disorder with ion mass is evident. 
TABLE I. Summary of implants and results of backscattering analyses.

\begin{tabular}{|c|c|c|c|c|c|c|c|c|}
\hline \multirow[b]{2}{*}{ Ion } & \multicolumn{2}{|c|}{ Implant } & \multirow[b]{2}{*}{$\begin{array}{l}\text { Impl. } \\
\text { temp. }\end{array}$} & \multicolumn{2}{|l|}{ As-implanted } & \multicolumn{3}{|c|}{ As-annealed } \\
\hline & $\begin{array}{l}E \\
\left(\mathrm{keV} \text { at }^{-1}\right)\end{array}$ & $\begin{array}{l}\text { Dose } \\
\text { (at } \mathrm{cm}^{-2} \text { ) }\end{array}$ & & $\begin{array}{l}\text { Crystal }(X) \text { or } \\
\text { amorphous }(a)\end{array}$ & $\begin{array}{l}\text { Amorphous } \\
\text { thickness } \\
(\AA \AA)\end{array}$ & $\chi_{\min }(\%)^{\mathrm{a}}$ & $\begin{array}{l}\text { No. of } \\
\text { displaced } \\
\text { atoms }\left(10^{16}\right. \\
\left.\text { at } \mathrm{cm}^{-2}\right)\end{array}$ & Comments ${ }^{\circ}$ \\
\hline $\mathrm{As}_{1}^{+}$ & 60 & $10^{14}$ & $100^{\circ} \mathrm{C}$ & $x$ & $\ldots$ & & & d.a. \\
\hline $\mathrm{As}_{2}^{+}$ & 60 & $10^{14}$ & $100^{\circ} \mathrm{C}$ & $x$ & $\ldots$ & & & d.a. \\
\hline $\mathrm{As}_{1}^{+}$ & 60 & $10^{14}$ & $\begin{array}{l}\mathrm{RT} \\
\mathrm{LN}_{2} \mathrm{~T}\end{array}$ & & & & & \\
\hline $\mathrm{As}_{2}{ }^{+}$ & 60 & $10^{14}$ & $R T$ & & & & & \\
\hline $\mathrm{As}_{4}^{+}$ & 60 & $10^{14}$ & $\begin{array}{l}\mathrm{LN}_{2} \mathrm{~T} \\
100^{\circ} \mathrm{C}\end{array}$ & $\mathbf{a}$ & 500 & 10 & 2.7 & $\mathrm{n}$ \\
\hline & & & $\begin{array}{l}\mathrm{RT} \\
\mathrm{LN}_{2} \mathrm{~T}\end{array}$ & & & & & \\
\hline $\mathrm{As}_{2}{ }^{\prime}$ & 60 & $5 \times 10^{14}$ & RT & $\mathbf{a}$ & 600 & 13 & 4.1 & n. \\
\hline $\mathbf{A s}_{2}^{+}$ & 60 & $10^{15}$ & RT & a & 600 & 18 & 5.3 & n. \\
\hline $\mathrm{As}_{2}{ }^{+}$ & 60 & $10^{15}$ & $\mathrm{LN}_{2} \mathrm{~T}$ & $\mathbf{a}$ & 650 & 26 & 7.2 & n. \\
\hline $\mathrm{Si}^{+}$ & 80 & $10^{14}$ & RT & $x$ & $\ldots$ & & & d.a. \\
\hline $\mathbf{S}^{+}$ & 80 & $10^{14}$ & RT & $x$ & $\ldots$ & & & d.a. \\
\hline $\mathbf{A s}_{1}{ }^{+}$ & 120 & $10^{14}$ & $\mathrm{RT}$ & a & 830 & 36 & 10.8 & n. \\
\hline $\mathrm{As}_{1}^{+}$ & 120 & $10^{14}$ & $L N_{2} T$ & a & 860 & 35 & 13.6 & n. \\
\hline $\mathrm{Ar}^{+}$ & 100 & $10^{14}$ & $100^{\circ} \mathrm{C}$ & $x$ & $\ldots$ & & & d.a. \\
\hline $\mathrm{Ar}^{+}$ & 100 & $10^{14}$ & RT & $a$ & 900 & & & s.r. \\
\hline $\mathrm{Ar}^{+}$ & 100 & $10^{14}$ & $\mathrm{LN}_{2} \mathrm{~T}$ & a & 1050 & 46 & 17.0 & n. \\
\hline $\mathrm{Si}^{+}$ & 80 & $10^{15}$ & $\mathrm{RT}$ & a & 1100 & 53 & 20.5 & n. \\
\hline $\mathrm{S}^{+}$ & 80 & $10^{15}$ & RT & a & 1100 & 46 & 19.0 & n. \\
\hline $\mathrm{As}_{1}{ }^{+}$ & 180 & $10^{14}$ & RT & a & 1100 & 43 & 20.0 & n. \\
\hline $\mathrm{Si}^{+}$ & 80 & $10^{16}$ & RT & a & 1350 & 57 & 27.7 & $\mathrm{n}$. \\
\hline $\mathrm{Si}^{+}$ & 80 & $10^{15}$ & $\mathrm{LN}_{2} \mathrm{~T}$ & a & 1550 & 51 & 30.5 & n. \\
\hline $\mathrm{Si}^{+}$ & 80 & $10^{16}$ & $\mathrm{LN}_{2} \mathrm{~T}$ & a & 1950 & 66 & 44.3 & $\mathrm{n}$. \\
\hline
\end{tabular}

"Measured immediately beneath the surface peak. Values for $\chi_{\min }$ and the areal density of displaced atoms are included only for samples that had a totally amorphous surface layer after implantation. For all other samples $\chi_{\min } \approx 8 \%$ and areal density of displaced atoms $\approx 1 \times 10^{16}$ at $\mathrm{cm}^{-3}$.

${ }^{b} \mathrm{~d}$.a: Defect annealing occurs (i.e., there is no moving crystal/damage interface). s.r: Surface regrowth from a layer of single crystal at the surface in addition to normal layer-by-layer regrowth from the amorphous/bulk crystal interface. $n$ : Normal layer-by-layer regrowth from the amorphous/bulk crystal interface.

\section{RESULTS}

The results of the channeling measurements after implantation and after the longest anneal times are summarized in Table I. Considering first our results for as-implanted samples, we found that the extent of the implantationinduced disorder increased considerably with increasing ion mass. This is illustrated in Fig. 1 by spectra from samples implanted at room temperature with $\mathrm{Si}^{+}, \mathrm{S}^{+}$and $\mathrm{Ar}^{+}$ions, each to a dose of $10^{14}$ ions $\mathrm{cm}^{-2}$. The implantation energies were chosen so that the ion ranges and range straggling were approximately the same $\left(R_{p} \sim 700 \AA, \Delta R_{p} \sim 450 \AA\right)$ yet the backscattering yields from the surface regions range from that typical of fairly good single-crystal for the Si $(28 \mathrm{amu})$ implantation to that of amorphous material for the $\operatorname{Ar}(40$ amu) implantation. Implantations of all three ions at $-196^{\circ} \mathrm{C}$ produced amorphous layers, but they showed a similar trend in that the thicknesses of the amorphous layers increased with increase of the ion mass. We attribute this behavior to a primary amount of radiation damage which increases with the mass of the implanted species and an annealing process which depends on the sample temperature.

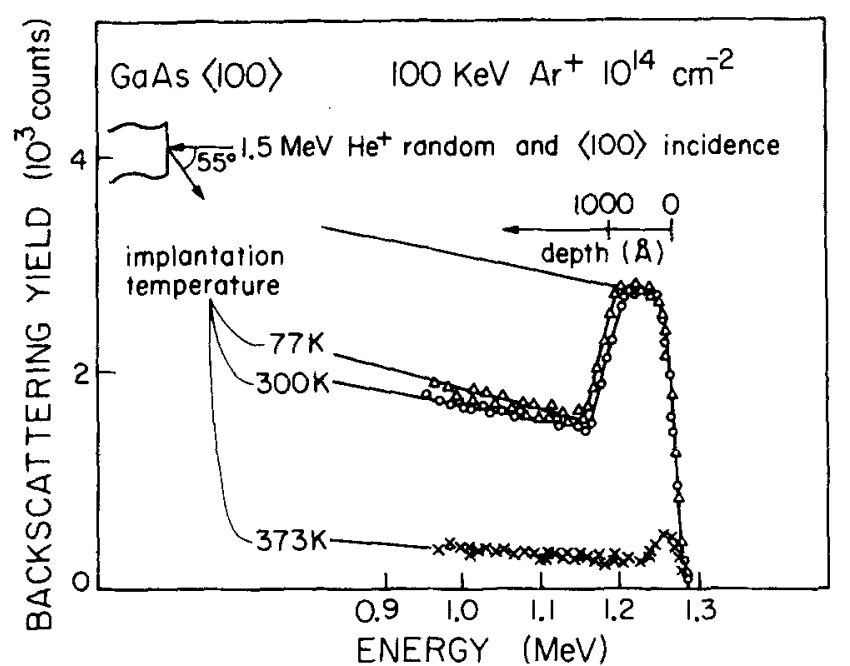

FIG. 2. Disorder profiles for GaAs implanted with $100-\mathrm{keV} \mathrm{Ar}^{+}$to $10^{14}$ ions $\mathrm{cm}^{-2}$ at different substrate temperatures. Self-annealing during implantation clearly increases with increase in the implantation temperature. 
The annealing is significant at room temperature, but decreases rapidly with decreasing substrate temperature during implantation, as is illustrated in Fig. 2. These spectra were obtained from samples implanted at different temperatures with $100-\mathrm{keV} \mathrm{Ar}^{+}$ions with a fixed dose of $10^{14}$ ions $\mathrm{cm}^{-2}$. It is possible that the sample implanted at $\mathrm{LN}_{2} \mathrm{~T}$ underwent some annealing on heating to room temperature, but we believe that this is unlikely in view of the insignificant annealing observed by Williams et al.$^{8}$ on heating from RT to $\sim 100^{\circ} \mathrm{C}$.

\section{Ga As $\langle\mid 00\rangle$}

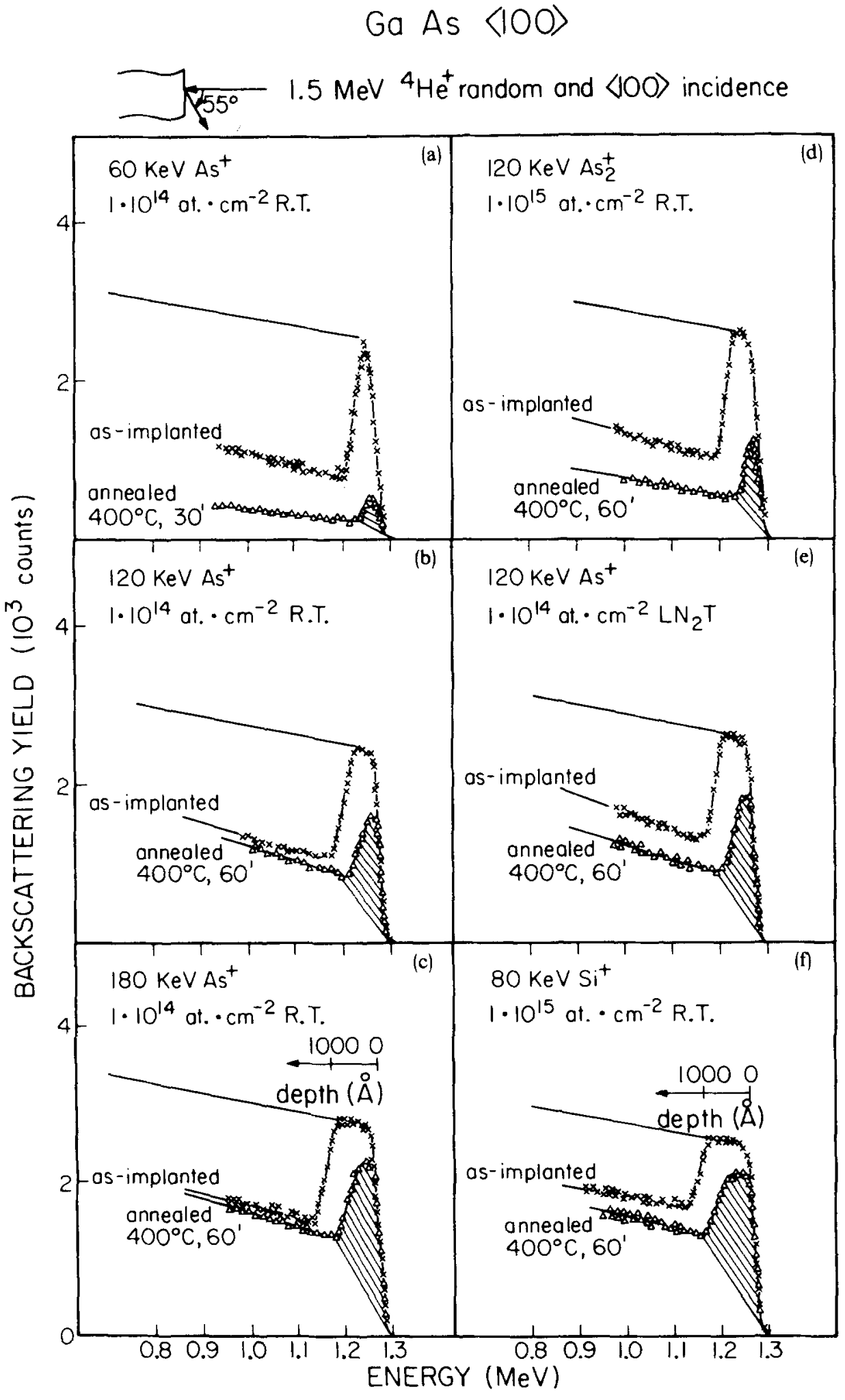

The annealing behavior to amorphous layers of different thicknesses as monitored by channeling is illustrated in detail for a range of different implantation conditions in Fig. 3. Figures 3(a), 3(b), and 3(c) show the disorder profiles before and after annealing for initial amorphous layer thicknesses of 500,830 , and $1100 \AA$, respectively-produced by implanting $\mathrm{As}^{+}$ions, all at room temperature and to doses of $10^{14}$ ions $\mathrm{cm}^{-2}$, but with energies of 60,120 , and $180 \mathrm{keV}$, respectively. Clearly, the quality of the regrown crystal is best for the thinnest amorphous layer and becomes worse with in-

FIG. 3. Annealing behavior of GaAs implanted under various conditions as labeled. The shaded portions were taken as the disorder peak areas. 


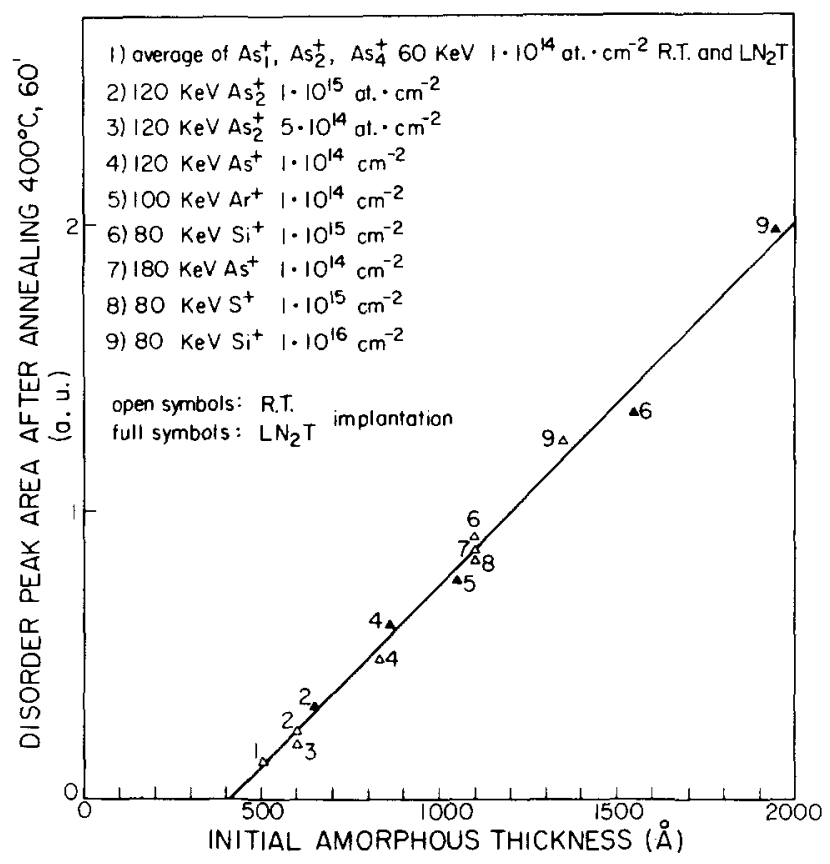

FIG. 4. Disorder peak area obtained from channeling measurements of implanted $\mathrm{GaAs}$ after annealing at $400^{\circ} \mathrm{C}$ for $60 \mathrm{~min}$ plotted against the thickness of the amorphous layer generated by implantation.

creasing amorphous thickness.

Figures 3(d), 3(e), and 3(f) show the disorder profiles of samples with the same initial amorphous thicknesses as in Figs. 3(a), 3(b), and 3(c), respectively, but produced with different implantations. The sample in Fig. 3(d) has the same implant species, energy, and substrate temperature as the sample in Fig. 3(a), but has a larger dose by an order to magnitude; Figs. 3(b) and 3(e) differ in their implantation temperatures; and Figs. 3(c) and 3(f) have different implantation species, energies, and doses. In each case, not only were the areas of the residual disorder peaks very similar after annealing, but the detailed shapes of the backscattering spectra were almost the same. It is also evident that for all six samples there was good regrowth of the deepest $\sim 400 \AA$ of amorphous material and poorer regrowth for the remainder.

To clarify the correlation between the thickness of the amorphous layer generated by ion implantation and the outcome of the annealing we have plotted in Fig. 4 the areas of the disorder peaks (which are proportional to the number of scattering centers per $\mathrm{cm}^{2}$ ), after furnace annealing at $400{ }^{\circ} \mathrm{C}$ for $60 \mathrm{~min}$ against the amorphous thicknesses. The amorphous thicknesses and disorder peak areas were determined from channeling spectra recorded before and after annealing, assuming a linearly rising background beneath each disorder peak as indicated in Fig. 3. Points are included for all of the samples that had a fully amorphous surface layer after implantation. The fact that all data points fit on a single curve proves that as a first approximation the thickness of the amorphous layer is the primary parameter of significance, irrespective of the ion species, implantation dose, or substrate temperature during the implantation. This figure also clearly establishes that the number of residual defects after annealing increases linearly with the initial thickness of the amorphous layer.
From our kinetics measurements, we know that very little further annealing of these samples can occur at this temperature. Also, recent work by Kular et al. ${ }^{6}$ has shown that a $2000-\AA$ amorphous layer generated by $\mathrm{Zn}^{+}$implantation into the $\mathrm{GaAs}$ is crystalline after annealing at $300^{\circ} \mathrm{C}$ for only $15 \mathrm{~min}$. Therefore we believe that the dependence reported in Fig. 4 cannot be explained simply in terms of imcomplete regrowth of the thicker layers, but rather reflects an intrinsic property of the regrowth mechanism in GaAs.

Extrapolation of the curve in Fig. 4 to lower initial amorphous thickness indicates "zero" residual disorder for the regrowth of a layer with an amorphous thickness $\leqslant 400$ $\AA$. This is consistent with the observation of $\sim 400 \AA$ of good initial regrowth in the spectra of Fig. 3.

It should be noted that since the vapor pressure of As over solid As is appreciable it is possible that As was lost from the amorphous GaAs during annealing. However, in view of the high regrowth speed of $\mathrm{GaAs},{ }^{6}$ we believe that $\mathrm{As}$ loss should not be sufficient to affect the surface crystallinity significantly.

TEM analyses were conducted on the samples of Figs. $3(b)$, and $3(e)$, and $3(f)$. Figure 5 shows TEM bright field planview micrographs of Figs. 3(b) and 3(e) before annealing [Figs. 5(a) and 5(c)] and after annealing [Fig. 5(b) and 3(d)].The plan-view of unannealed specimens both from RT [Fig. 5(a)] and $\mathrm{LN}_{2} \mathrm{~T}$ [Fig. 5(c)] implants were featureless. TED patterns from both specimens had diffuse rings without single-crystal spots at thin regions $(\leqslant 500 \AA)$, indicating the presence of continuous amorphous layers extending to their top surfaces. The annealing of those samples at $400{ }^{\circ} \mathrm{C}$ for 60 min produced coarse dark patches. TED patterns from the thin surface regions $(\leqslant 500 \AA)$ showed no diffuse rings; rather, they showed (100) single-crystal spots together with irregularly distributed extra spots.

In Fig. 6 the bright field plan-view micrographs for the sample of Fig. 3(f) before [Fig. 6(a)] and after annealing [Fig. $6(b)]$ are shown. The results for the unannealed specimen were similar to those obtained for $\mathrm{As}^{+}$implants except for the presence of dark dots on the otherwise featureless background. Annealing at $400^{\circ} \mathrm{C}$ again resulted in the formation of irregularly shaped coarse dark patches. The fine background in this case contained fringes, thought to be moiré fringes. The TED pattern contained (100) single-crystal spots together with a regular array of streaked extra spots indicating twinning.

If the implantation causes amorphization, but leaves a layer of single-crystal on the surface, then there is regrowth from both crystalline/amorphous interfaces. This is illustrated in Fig. 7 with the spectra obtained from a sample that had been implanted with $100-\mathrm{keV} \mathrm{Ar}{ }^{+}$to $10^{14}$ ions $\mathrm{cm}^{-2}$ at $R T$. The presence of a thin crystalline layer after ion implantation is indicated by a channeling yield at the surface that is lower than the random level. The spectrum from the annealed sample showed that there has been good initial regrowth from both sides of the amorphous layer, but there was relatively high residual disorder in the middle-presumably where the two moving crystal/amorphous interfaces met.

Bright field micrographs and TED patterns from this 
sample are shown in Fig. 8. The results from the unannealed specimen [Fig. 8(a)] showed a spotty structure indicating the presence of damage clusters. In the TED pattern the simultaneous presence of single-crystal spots and amorphous rings confirmed the existence of an amorphous layer and a monocrystalline layer. The annealing at $400^{\circ} \mathrm{C}$ [Fig. 8(b)] caused the damage clusters to grow bigger in size as compared to the unannealed specimens, but no amorphous or twinned material was evident from the TED pattern.

Figure 9(a) is a TEM cross-sectional view of the sample of Figs. 7 and 8 after annealing. Two damage regions are evident: one with high damage $\sim 600 \AA$ wide located $\sim 230$ $\AA$ from the surface and another $\sim 450 \AA$ wide located immediately below it with a lower damage density. The top $\sim 230$ $\AA$ of the sample were free of damage detectable by TEM. While the backscattering spectrum of Fig. 7 does not distinguish two different buried damage regimes it shows that $\sim 250 \AA$ of single crystal is present on the surface in good agreement with the TEM result.

Figure $9(b)$ is a TEM cross-sectional view of the sample of Figs. 3(b) and 5(b) implantation at RT with 120-keV As ${ }^{+}$ to a dose of $10^{14}$ ions $\mathrm{cm}^{-2}$ after annealing. It shows a continuous band of damage $\sim 560 \AA$ wide at the surface and a line of small damage clusters at a mean depth of $900 \AA$. The $\sim 350$ - $\AA$ region between the damage band and layer of clusters was free of defects visible to TEM. Plan-view micrographs showed that the damage band contained microtwins, precipitates and misoriented crystal structure.

\section{DISCUSSION}

From the results so far reported, we believe that the epitaxial regrowth of amorphous ion-implanted GaAs proceeds, at least initially, in a layer-by-layer fashion. Figure 7

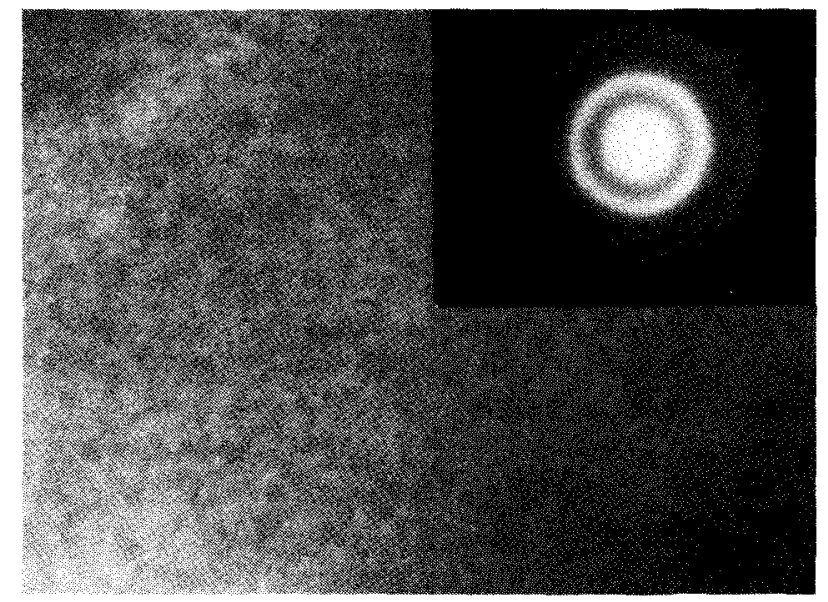

(a)

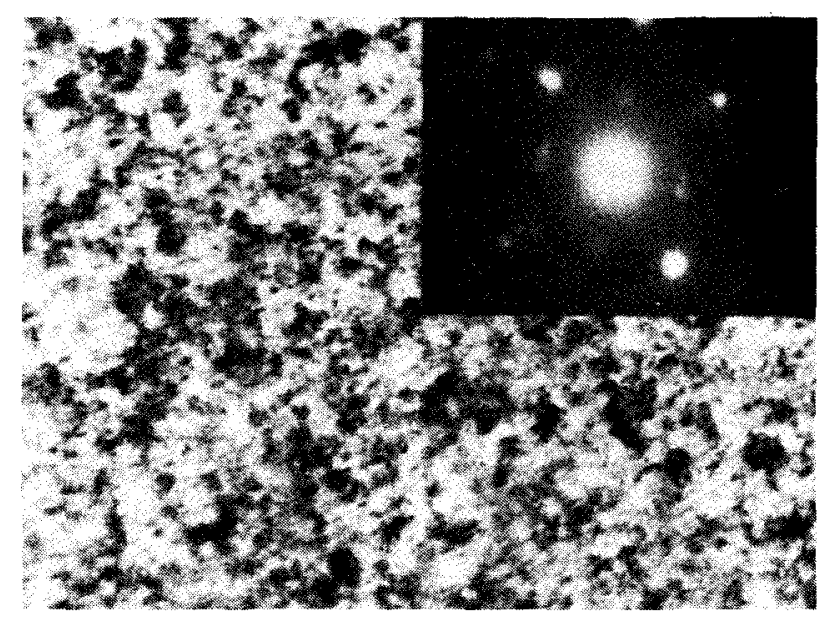

(b)

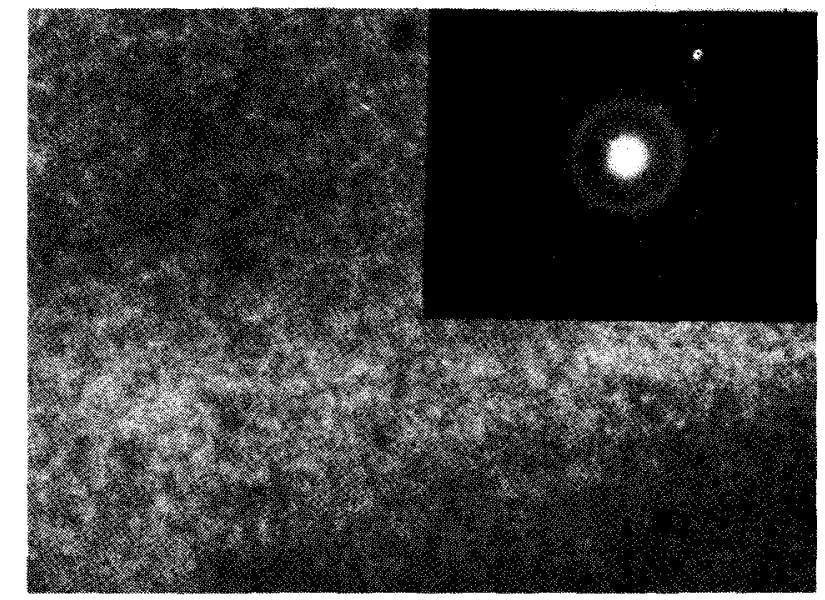

(c)

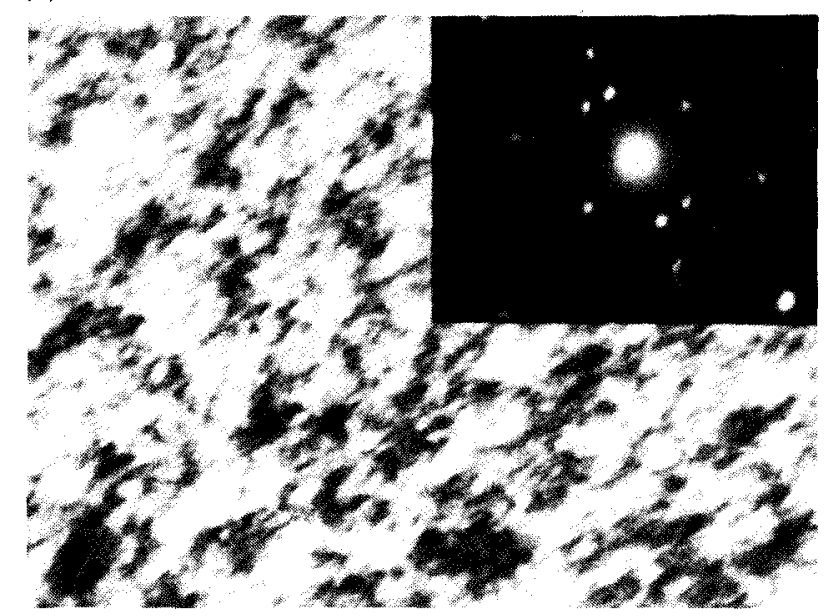

(d)

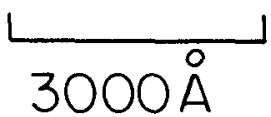

FIG. 5. TEM bright field plan-view micrographs of GaAs samples implanted with (a) and (b) $120-\mathrm{keV} \mathrm{As}^{+}$to doses of $10^{14}$ ions $\mathrm{cm}{ }^{-2}$ at RT and (c) and (d) $\mathrm{LN}_{2} \mathrm{~T}$. (a) and (c) were taken from unannealed samples and (b) and (d) were from samples that had been annealed at $400{ }^{\circ} \mathrm{C}$ for $60 \mathrm{~min}(\mathrm{~g}=220) . \mathrm{Diffraction}$ patterns are inset. 


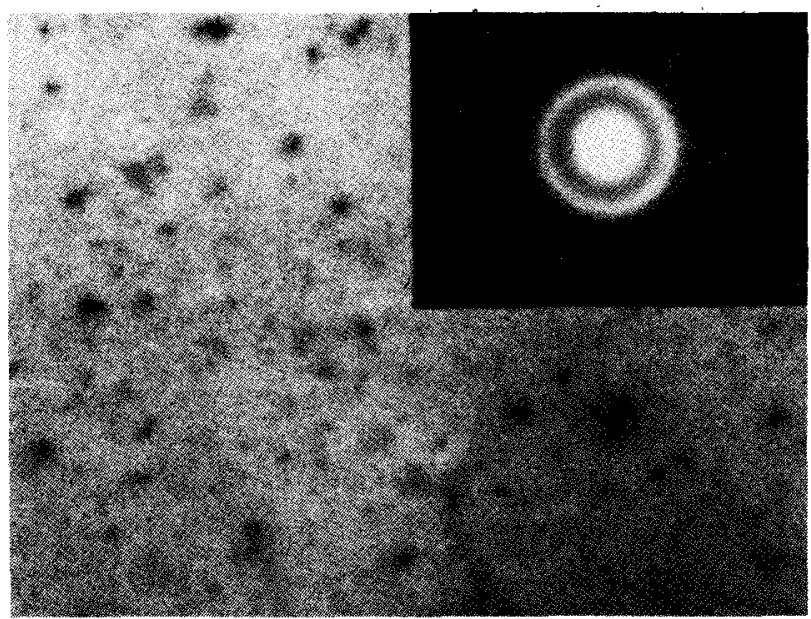

(a)

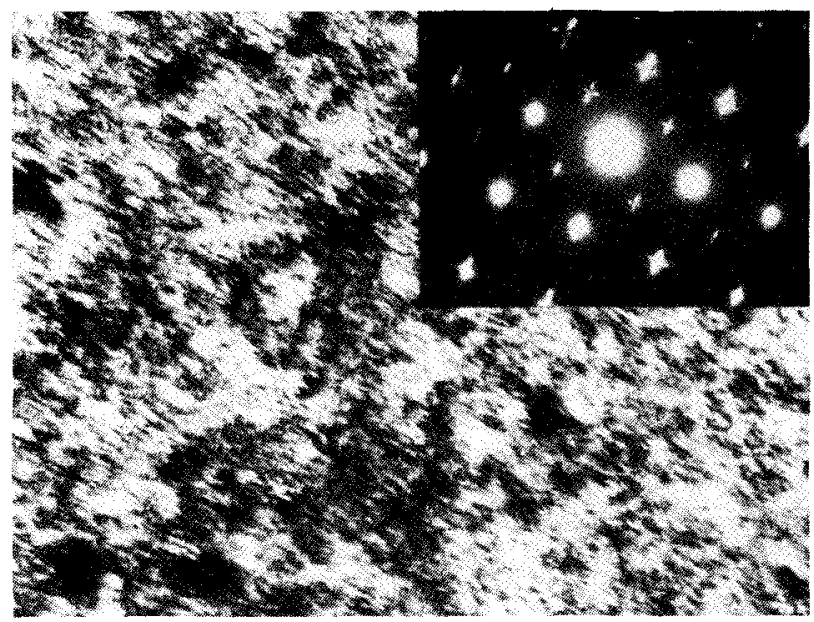

(b)

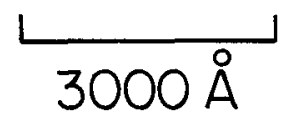

FIG. 6. TEM bright field plan-view micrographs of samples implanted with $10^{15}$ ions $\mathrm{cm}^{-2}$ of $80-\mathrm{keV} \mathrm{Si}^{+}$at $\mathrm{RT}$ (a) before and (b) after annealing at $400{ }^{\circ} \mathrm{C}$ for $60 \mathrm{~min}$. Diffraction patterns are inset.

provides suggestive evidence for this mechanism in that two moving crystal-amorphous interfaces coming from opposite sides appear to have met, leaving a disorder peak at $\sim 400 \AA$. A layer-by-layer regrowth mechanism has been observed in ion-implanted $\mathrm{Si}$ and $\mathrm{Ge} .{ }^{10,11}$ This mechanism in the latter materials is characterized by definite activation energies ${ }^{11}$ and different regrowth rates for different crystal orientations. ${ }^{11}$

The regrowth velocity in ion-implanted GaAs must be high compared to Ge and Si. Kular et al. ${ }^{6}$ observed complete regrowth of a $2000-\AA$ thick amorphous layer in (100) GaAs after annealing at $300^{\circ} \mathrm{C}$ for only $15 \mathrm{~min}$. This implies a minimum regrowth rate of $\sim 130 \AA \mathrm{min}^{-1}$, compared with regrowth rates at this temperature of $\sim 3.10^{-5} \AA \min ^{-1}$ (by extrapolation of existing data) for $\mathrm{Si}$ and $65 \AA \mathrm{Amin}^{-1}$ for $\mathrm{Ge}$.

That kinetics measurements to determine the regrowth rate and its activation energy have not been successfully per-

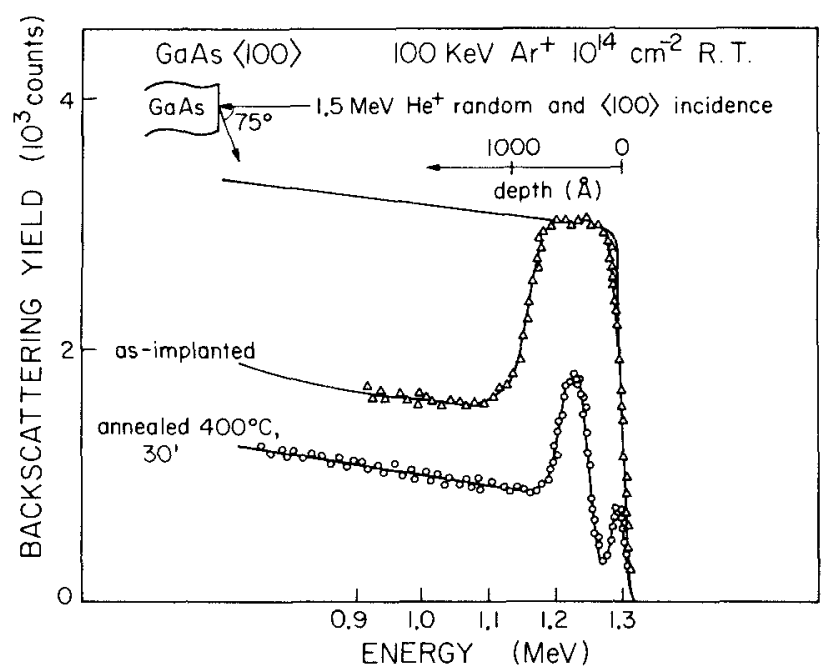

FIG. 7. Backscattering energy spectra of 1.5- $\mathrm{MeV} \mathrm{He}^{+}$at random and $\langle 100\rangle$ incidence for GaAs implanted at room temperature with $100-\mathrm{keV}$ $\mathrm{Ar}^{+}$to $10^{14}$ ions $\mathrm{cm}^{-2}$ and after annealing at $400^{\circ} \mathrm{C}$ for $30 \mathrm{~min}$. The implantation created an amorphous layer with a thin layer of single crystal at the surface. Annealing caused regrowth from the crystalline/amorphous interfaces on both sides of the amorphous layer.

formed so far can be explained by the fact that the regrowth speed is so high for low-temperature annealing $\left(200-600^{\circ} \mathrm{C}\right)$ and the fact that the regrown epitaxial crystal is heavily damaged, making it difficult to identify the location of the crystalline/amorphous interface. However, there is evidence $^{5}$ that the regrowth velocity for the $(111\rangle$ direction in $\mathrm{GaAs}$ is lower than the velocity in the $\langle 100\rangle$ direction, as one would expect from the results observed for $\mathrm{Si}$ and $\mathrm{Ge}$.

From our results, it appears that very thin amorphous layers of $\mathrm{GaAs}$ can be regrown free of extended defects for $\sim 400 \AA$ at a temperature of $400{ }^{\circ} \mathrm{C}$ (see the extrapolation to zero disorder in Fig. 4) and that after this distance the number of residual defects increases linearly with the thickness of the amorphous layer. To explain these observations, we suggest a model in which the growing crystal front accumulates local defects at $400 \AA$ represents the maximum distance that the interface can move before the defects begin to precipitate in clusters. Presumably, these clusters are stable structures which can only be removed by annealing at higher temperatures $\left(\sim 700-900^{\circ} \mathrm{C}\right) .^{6}$ We suggest that the buildup of these clusters of defects promotes the formation of $\langle 111\rangle$ facets that will act as nucleation centers for microtwins. Similar annealing behavior has been observed in TEM studies by Drosd et al. ${ }^{12}$ on Si. They observed that there was an "incubation" period before (111) facets could be formed in (100) $\mathrm{Si}$ and that these facets then acted as nucleation centers for the growth of twins. Similarly, Revesz found a correlation between the presence of Ar bubbles at the amorphous/crystalline interface in $\mathrm{Ar}^{+}$implanted $\mathrm{Si}$ and the nucleation of twins and crystallites with different orientations. ${ }^{13}$

The nature of these clusters of defects is not clear, but it has recently been reported ${ }^{14,15}$ that $\mathrm{Cr}$ in GaAs is mobile at temperatures as low as $\sim 350-400^{\circ} \mathrm{C}$. Therefore it is conceivable that impurities such as $\mathrm{Cr}$ are involved in the nucleation of the twins. However $\mathrm{Cr}$ precipitates after heat treat- 


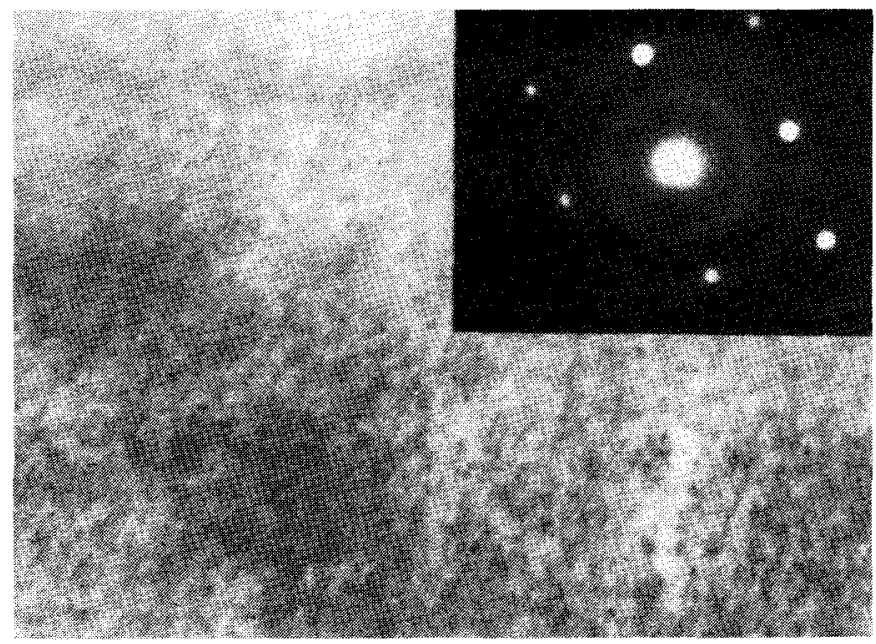

(a)

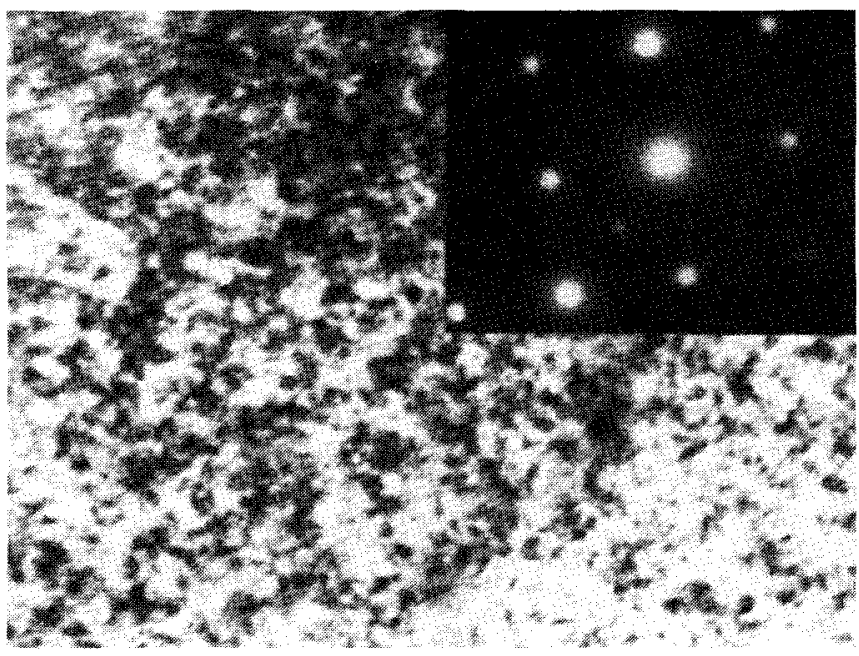

(b)

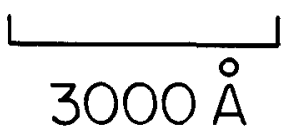

FIG. 8. TEM bright field micrographs of samples implanted with $100-\mathrm{keV}$ $\mathrm{Ar}^{+}$ions at RT to a dose of $10^{14}$ ions $\mathrm{cm}^{-2}$ (a) before and (b) after annealing at $400^{\circ} \mathrm{C}$ for $30 \mathrm{~min}(\mathrm{~g}=220$ ). Diffraction patterns are inset.

ment at $\sim 800^{\circ} \mathrm{C}$ were not seen in TEM studies of GaAs samples where $\mathrm{Cr}$ gettering was known to have occurred. ${ }^{16}$

It has been suggested that the initial epitaxial regrowth of implanted GaAs during low-temperature annealing can be explained in terms of the recovery of a transition region between the fully amorphous region and the undamaged crystalline substrate. ${ }^{5}$ Our results indicate that if this transition region exists it must be $\sim 200 \AA$ or less. This can be seen in Fig. 7 where high resolution channeling measurements $(\Delta t \leqslant 150 \AA)$ reveal a very sharp interface between the implanted layer and the crystalline substrate. One would also expect that the width of such regions would depend on the energy straggling of the implanted species and consequently would increase with the energy of the implanted species, but this is not observed (see Figs. 3 and 4). Also the recent results of Kular et al. ${ }^{6}$ indicate that the thickness of the layer that regrows without extended defects increases with increasing annealing temperature. This result is not consistent with the assumption of a transition layer of fixed thickness.

Further evidence supporting the model proposed here is also found in the results of Figs. 7 and 8 where the regrowth clearly took place on both sides of the amorphous layer. The thickness of the initial amorphous layer was $\sim 800 \AA$. After annealing, $400 \AA$ had regrown from both sides (Fig. 7). According to the model, the precipitation of defects should then barely have begun, so that the regrown crystal should have been free of extended defects. This is indeed what is observed (Fig.8).

We now discuss the trends that we have observed by backscattering analysis in terms of this model. We expect bulk twinned material to cause dechanneling of the incident beam as opposed to simple direct point scattering. This is because there is a precise relationship between the orientation of the host material and that of the twinned lattice. For example, the $\langle 100\rangle$ directions in perfectly regrown material are exactly parallel to the $\langle 221\rangle$ direction in twinned material. Consequently, particles that are initially channeled along the $\langle 100\rangle$ direction in nondefective material will be channeled into $\langle 221\rangle$ axial rows in the twinned lattice. Since the dechanneling rate in virgin crystal for the 221$\rangle$ direction is $\sim 10$ times larger than that in the $\langle 100\rangle$ direction, twinned material will cause substantial dechanneling. On the other hand, twin boundaries represent partially blocked channels and therefore give rise to direct scattering. The ratio of direct scattering to dechanneling from twinned regions will depend on the surface-to-volume ratio for the twins. Thus for large twinned regions (diameters $\sim 2000-3000 \AA$ ) when the volume contribution of twinned regions ${ }^{17}$ exceeds $10 \%$ we ex-

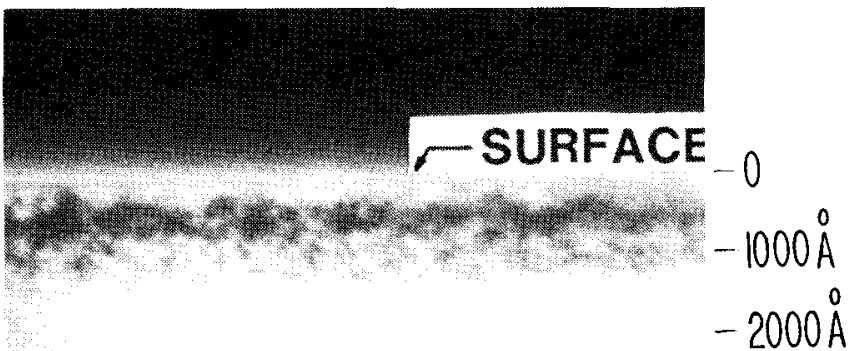

(a)

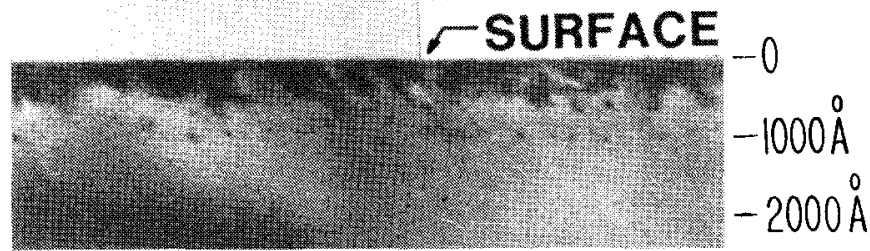

(b)

FIG. 9. Cross-sectional TEM bright field micrographs: (a) 100-keV $10^{14}$ ions $\mathrm{cm}^{-2} \mathrm{RT} \mathrm{Ar}^{+}$implant; $400^{\circ} \mathrm{C} 30$-min furnace anneal. (b) $120-\mathrm{keV} 10^{14}$ ions $\mathrm{cm}^{-2} \mathrm{RT} \mathrm{As}^{+}$implant; $400^{\circ} \mathrm{C} 60$-min furnace anneal. 
pect high dechanneling relative to direct scattering whereas for small twins the direct scattering from the twin boundaries will dominate. Now TEM dark field micrographs (not included here) showed that the dimensions of the twins in the regrown GaAs varied from less than 300 to $\sim 600 \AA$ across. The smaller size twinned material was present in $\mathrm{As}^{+}$-implanted $\mathrm{GaAs}$ while the larger size was present in the $\mathrm{Si}^{+}$implanted GaAs. Because of this small size of the twins we conclude that the scattering we observed in our backscattering spectra is mainly direct scattering due to the microtwins together with any residual point defects, and that dechanneling can be neglected in the analysis of the spectra. This is consistent with our observations in that a calculation of the $\chi_{\min }$ as a function of the number of scattering centers, assuming direct scattering only, gives values very close to those we observed experimentally. The observation that the average diameter of the twins changes with the implanted species indicates that while the regrown thickness before the nucleation of twins is largely independent of the parameters of the ion implantation, there are variations in the outcome of the regrowth with these parameters which are not observable by channeling.

To investigate the effect of the initial amorphous layer on the concentration of residual defects after annealing, we have plotted in Fig. 10 the ratio of the area of the disorder peak after annealing to the area due to the amorphous layer after implantation (as obtained by channeling measurements) against the thickness of the initial amorphous layer. The ratio is proportional to the concentration of residual defects. If it is equal to one then no regrowth has occurred, while if it is close to zero, a good crystal was produced by the annealing. Since this ratio is also independent of the conditions used for the analysis (energy of the analyzing beam, angle of detection of scattered particles, etc.) values taken from other references ${ }^{5,6}$ could be included in the same plot. It is evident from the figure that the data from these references are in reasonable agreement with our results. An additional point could be included ${ }^{7}$ but has been omitted because of uncertainties in the reported parameters. ${ }^{18}$ The plot seems to indicate the presence of two different regrowth regimes:

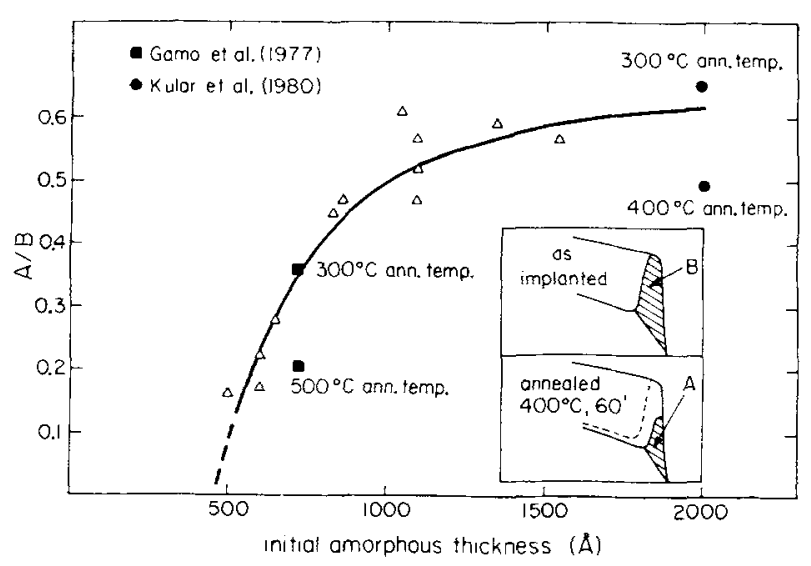

FIG. 10. Ratio of the area of the disorder peak after annealing to the area of the peak after implantation plotted against the thickness of the initial amorphous layer.
(1) where the defect concentration after annealing increases with an increase in the initial amorphous thickness, and (2) where the defect concentrations stay at a constant value, independent of the initial amorphous thickness. According to our model, this can be interpreted as follows: The first regime corresponds to the region in the material where the precipitation of clusters of local defects takes place so that microtwins nucleate with the result that the defect concentration increases with the thickness of the initial amorphous material. The second regime represents the region where the defect concentration has reached its equilibrium value so that it will stay constant with increasing thickness of the initial amorphous layer. By "equilibrium value" for the defect concentration, we mean that for every twinned region that is terminated, another twinned region is nucleated. In fact, from dark field TEM we know that the twins do not extend to the surface so that uniform nucleation of new microtwins throughout this second region is necessary in order to explain the results obtained.

From the results so far presented and our interpretation of them, it appears that it is possible with annealing at $400^{\circ} \mathrm{C}$ to regrow thin layers $\mathrm{GaAs}$ without nucleation of twins provided the initial amorphous layer is $\sim 400 \AA$ or less. Such a possibility would be of real practical significance and deserves further investigation. It would also seem most desirable to obtain more experimental results to further test the regrowth model presented here. In addition, it would be of interest to conduct measurements of electrical properties such as electron mobilities and the densities of compensating centers in samples similar to those employed in this work.

\section{ACKNOWLEDGMENTS}

We would like to thank Professor S. "Fernando" Lau of the University of California, San Diego, for encouragement and helpful advice throughout the course of this work. We also thank Professor Jack Washburn of the University of California, Berkeley, for useful discussions, M. Parks for much secretarial assistance, and D. Tonn for help with the implantations. This work was supported in part by the Advanced Research Project Agency of the Department of Defense and was monitored by the Air Force Office of Scientific Research under Contract No. F-49620-77-C-0087. Financial support was also received from the Basic Research Division of the Department of Energy through the Materials and Molecular Research Division of the Lawrence Berkeley Laboratory.

'F. H. Eisen, J. S. Harris, B. Welch, R. D. Pashley, D. Sigurd, and J. W. Mayer, in Ion Implantation in Semiconductors and Other Materials, edited by Billy L. Crowder (Plenum, New York, 1973), p. 631.

${ }^{2}$ J. S. Harris, F. H. Eisen, B. Welch, J. D. Haskell, R. D. Pashley, and J. W. Mayer, Appl. Phys. Lett. 21, 601 (1972).

${ }^{3}$ F. H. Eisen, B. M. Welch, H. Müller, K. Gamo, T. Inada, and J. W. Mayer, Solid State Electron. 20, 219 (1977).

${ }^{4}$ G. Carter, W. A. Grant, J. D. Haskell, and G. A. Stephens, in Ion Implantation, edited by F. H. Eisen and L. T. Chadderton (Gordon and Breach, London, 1971), p. 261.

${ }^{5}$ K. Gamo, T. Inada, J. W. Mayer, F. H. Eisen, and C. G. Rhodes, Rad. Effects 33, 85 (1977). 
'S. S. Kular, B. J. Sealy, K. G. Stephens, D. Sadana, and G. R. Booker, Solid State Electron. 23, 831 (1980).

${ }^{7}$ J. S. Williams and M. W. Austin, Nucl. Instrum. Meth. 168, 307 (1980).

${ }^{8}$ J. S. Williams and M. W. Austin, Appl. Phys. Lett. 36, 994 (1980).

'B. R. Appleton and G. Foti, in Ion Beam Handbook for Material Analysis, edited by J. W. Mayer and E. Rimini (Academic, New York, 1977), p. 67

${ }^{10}$ D. K. Sadana, M. Strathman, J. Washburn, C. W. Magee, M. Mäenpää, and G. R. Booker, Appl. Phys. Lett. 37, 615 (1980).

"S. S. Lau and W. F. van der Weg, in Thin Films-Interdiffusion and Reactions, edited by J. M. Poate, K. N. Tu, and J. W. Mayer (Wiley, New York, 1978), Chap. 12.

${ }^{12}$ B. Drosd and J. Washburn, J. Appl. Phys. 51, 4106 (1980).
${ }^{13}$ P. Revesz, M. Wittmer, J. Roth, and J. W. Mayer, J. Appl. Phys. 49, 5199 (1980).

${ }^{14}$ T. J. Magee, J. Peng, J. D. Hong, V. R. Deline, and C. A. Evans, Jr., App. Phys. Lett. 35, 615 (1980).

${ }^{15} \mathrm{~T}$. J. Magee, K. S. Lee, R. Ormond, C. A. Evans, Jr., R. J. Blattner; and C. Hopkins, Appl. Phys. Lett. 37, 635 (1980).

${ }^{16}$ T. J. Magee, J. Peng, J. D. Hong, C. A. Evans, Jr., V. R. Deline, and R. M. Malbon, Appl. Phys. Lett. 35, $277(1979)$.

${ }^{17}$ G. Foti, L. Csepregi, E. F. Kennedy, J. W. Mayer, P. P. Pronko, and M. D. Rechtin, Philos. Mag. A 37, 591 (1978).

${ }^{18} \mathrm{~J}$. S. Williams (private communication). 